\title{
The Mind and Liver Test: A New Approach to the Diagnosis of Minimal Hepatic Encephalopathy in Resource-Poor Settings
}

\author{
Saurav Das, ${ }^{1}$ Sajjadh M. J. Ali, ${ }^{1}$ James Seward, ${ }^{2}$ and Jayanthi Venkataraman ${ }^{3}$ \\ ${ }^{1}$ Department of Medical Gastroenterology, Stanley Medical College and Hospital, Chennai 600001, India \\ ${ }^{2}$ Banner Alzheimer's Institute, E Willetta Street, Phoenix, AZ 85006, USA \\ ${ }^{3}$ Global Health City, Perumbakkam, Chennai, Tamil Nadu 600100, India \\ Correspondence should be addressed to Saurav Das; sauravmed@gmail.com
}

Received 4 September 2014; Revised 11 November 2014; Accepted 12 November 2014; Published 8 December 2014

Academic Editor: Daisuke Morioka

Copyright (C) 2014 Saurav Das et al. This is an open access article distributed under the Creative Commons Attribution License, which permits unrestricted use, distribution, and reproduction in any medium, provided the original work is properly cited.

\begin{abstract}
Background and Aims. Minimal hepatic encephalopathy (MHE) is diagnosed using neuropsychometric tests or neurophysiological tests that are either inapplicable to illiterate patient population in resource-poor settings or require sophisticated and expensive equipment. The available tests assess discrete domains of mental impairment. Our aim was (a) to design a neuropsychometric test that measures all domains of mental impairment in MHE using one metric; (b) to evaluate its sensitivity, specificity, and reproducibility. Methods. The mind and liver test (MALT), a psychometric test assessing cognition, memory, and psychometric impairment, each on a scale of 20, was designed keeping in mind the requirements of a universal test. 40 cirrhotics and 36 controls were subjected to critical flicker frequency (CFF) and MALT in same sitting. ROC curve was plotted for MALT using CFF as gold standard. Bland-Altman plot was used to find test-retest agreement. Results. CFF values and MALT scores varied significantly between the cases and the controls $(P<0.05)$. MALT was $94 \%$ sensitive and $83 \%$ specific. Using ROC with CFF as gold standard, the AUC for diagnosis of MHE using MALT score was 0.89. Test-retest agreement was high $(\mathrm{ICC}=0.89)$. Conclusion. In this pilot study, MALT proved to be highly sensitive, specific, inexpensive, and reproducible.
\end{abstract}

\section{Introduction}

Hepatic encephalopathy is a major complication of cirrhosis. It is characterized by neuropsychiatric manifestations. In minimal hepatic encephalopathy (MHE), patients have alterations in sleep pattern, and there is difficulty in performing even day-to-day routine activities like driving a vehicle, doing simple calculations, and so forth [1-3]. This is often due to an impairment in multiple faculties of the mind. Initially there is a mild impairment in cognition and psychomotor skills which then progress to a gross impairment in orientation and general consciousness. These manifestations are potentially reversible, especially, if the diagnosis is made early in the course of the disease $[4,5]$.

The diagnosis of minimal hepatic encephalopathy (MHE) is made using a battery of neuropsychometric or neurophysiological tests [2]. The existing neuropsychometric tests include paper-pencil tests like the number connection tests $\mathrm{A}$ and $\mathrm{B}$, the figure connection test (FCT), trail tracing test, block design test, digit symbol test, and the comparatively recent inhibitory control test [6]. Inaccuracies in the paperpencil tests have been widely reported $[7,8]$. Also, there is a lack of consensus on the diagnostic criteria and a limited correction for educational level and age in these studies [4]. The FCT was designed for the Indian population and has been widely accepted as a sensitive test to detect MHE in illiterate individuals [9]. However, this test assesses only a few discrete domains of impairment (attention and psychomotor skills). Similarly the inhibitory control test primarily assesses attention deficit [10]. As a result, much of the tests hitherto mentioned are seldom used in day-to-day clinical practice [11]. More recent objective neurophysiological tests include critical flicker frequency (CFF) and, auditory and visual evoked potentials. All these tests involve expensive specialized equipment and trained experienced personnel [7, 11]. There is therefore a need to design an inexpensive test which would measure all the impaired domains of the mind using the same metric [12]. 
We designed a test that would examine the three important domains - cognition, memory, and psychomotor skillsand used this test in patients with chronic liver disease to detect MHE.

\section{Materials and Methods}

2.1. Design of the Mind and Liver Test (MALT). The impaired domains of mental function in MHE have an impact on the quality of daily life [13]. The mind and liver test (MALT) was conceptualized on a scientific basis and was designed to measure the daily mental needs of an individual as a whole, and not for just one specific domain. MALT was designed such that it served as a single metric measure for all impaired domains like cognition, memory, and psychometric skills.

In order to design the specific tasks which make up the MALT, a questionnaire investigating the specific daily mental demands encountered by the target population was administered to 100 individuals attending the out-patient liver clinic of Institute of Gastroenterology and Hepatology, Stanley Hospital, Chennai, India. Except for 5 patients who were either professionals or businessmen, the rest belonged to lower socioeconomic status and were laborers, unskilled workers, or farmers (Kuppuswamy's socioeconomic status scale) [14]. Based upon the results of the questionnaire, MALT items were chosen to be relevant to these daily demands.

For cognition the questions were designed to identify certain animals, ability to follow the sequence of a natural phenomenon (e.g., morning-noon-evening-night), and ability to perform simple mathematical calculations needed during daily transactions (e.g., transaction at the shop). For memory the questions tested immediate, short term, and long term recall separately. We also tested the ability to recall a visual as well as an auditory experience. The psychomotor abilities were tested by asking the patient to copy certain figures on a calibrated graph paper, to build a threedimensional structure of a wall using building blocks, to cut along a drawn line using a scissor, and to trace along a narrow path (analogous to a line tracing test).

All the three tests were designed using a colorful board, set of printed question cards, plastic building blocks, animal models, an audio device, and an instruction cum scoring sheet. For convenience, the three components of neuropsychometric analysis were color coded. Red steps tested memory, green steps tested cognition, and yellow steps tested psycho-motor skills [15].

These tasks were grouped into three different sections:

Section 1: figure the field,

Section 2: home sweet home,

Section 3: road not taken.

Section 1 included steps like identification of animals and vegetables on the countryside/neighborhood, and identification of well-known sequences of events like sowing seeds, transplanting the saplings, harvesting, and finally transporting to the city. In this section, we also asked the patient to build a wall using blocks. The failure to
TABLE 1: MALT-steps summary.

\begin{tabular}{|c|c|c|}
\hline Section & Task & $\begin{array}{l}\text { Corresponding mental } \\
\text { function }\end{array}$ \\
\hline \multirow{5}{*}{$\begin{array}{l}\text { (1) Figure the } \\
\text { field }\end{array}$} & Copy the figures & Visuospatial abilities \\
\hline & Group similar objects & Recognition \\
\hline & Trace the sequence & Executive function \\
\hline & Name the animals & Naming \\
\hline & Build the wall & Constructional ability \\
\hline \multirow{5}{*}{$\begin{array}{l}\text { (2) Home } \\
\text { sweet home }\end{array}$} & Complete the task & Executive function \\
\hline & $\begin{array}{l}\text { Remember the } \\
\text { arrangement }\end{array}$ & $\begin{array}{l}\text { Immediate visual } \\
\text { memory }\end{array}$ \\
\hline & Cut along the line & Psychomotor skills \\
\hline & Recall the steps & Attention \\
\hline & Identify the sound & Auditory recall \\
\hline \multirow{6}{*}{$\begin{array}{l}\text { (3) The road } \\
\text { not taken }\end{array}$} & Trace the path & Psycho-motor skills \\
\hline & What from shop? & Delayed visual recall \\
\hline & How much to pay? & Calculation \\
\hline & $\begin{array}{l}\text { Choose the shortest } \\
\text { path. }\end{array}$ & Decision making \\
\hline & Quiz & Divided attention \\
\hline & $\begin{array}{l}\text { Time, space, and } \\
\text { reason }\end{array}$ & $\begin{array}{l}\text { Abstraction | } \\
\text { Orientation }\end{array}$ \\
\hline
\end{tabular}

perform this task was considered a sign of psycho-motor impairment.

Section 2 included steps like remembering the arrangement of things on the shelves at home and ability to narrate the steps of a task performed at home daily, such as washing a cloth or making tea. Impairment in memory and organization reflected directly on the performance in these steps. In the same section we tested the ability of the patient to identify and remember sounds by using different stimuli, such as a church bell or an ambulance siren. Examinees were also asked to cut paper using a pair of scissors, a measure of psychomotor abilities.

Section 3 included tasks that tested the numerical abilities of the patient (like we asked the patient to perform small transactions at the shop) and tasks that asked them to identify places that they may visit on a daily basis, like a temple, a water pump, or a market place. Short term memory was tested by asking the patient to recall the short list of things to buy from the shop that was narrated to him in Section 2. We included a test analogous to the trail tracing test in Section 3 where the patient had to negotiate a narrow path from the shop back to home, using his index finger along the trail. Performance on this step can be impaired in patients with psycho-motor impairment.

Two other tests were performed on the MALT board, which could affect the daily activities in MHE. These included (a) divided attention: ability to observe images on the board that were not included as a part of the task; (b) judgment ability: to select the shortest of the three shown paths. Table 1 shows the steps included in the three sections of the test that appear on the MALT board (Figure 1) and the corresponding 


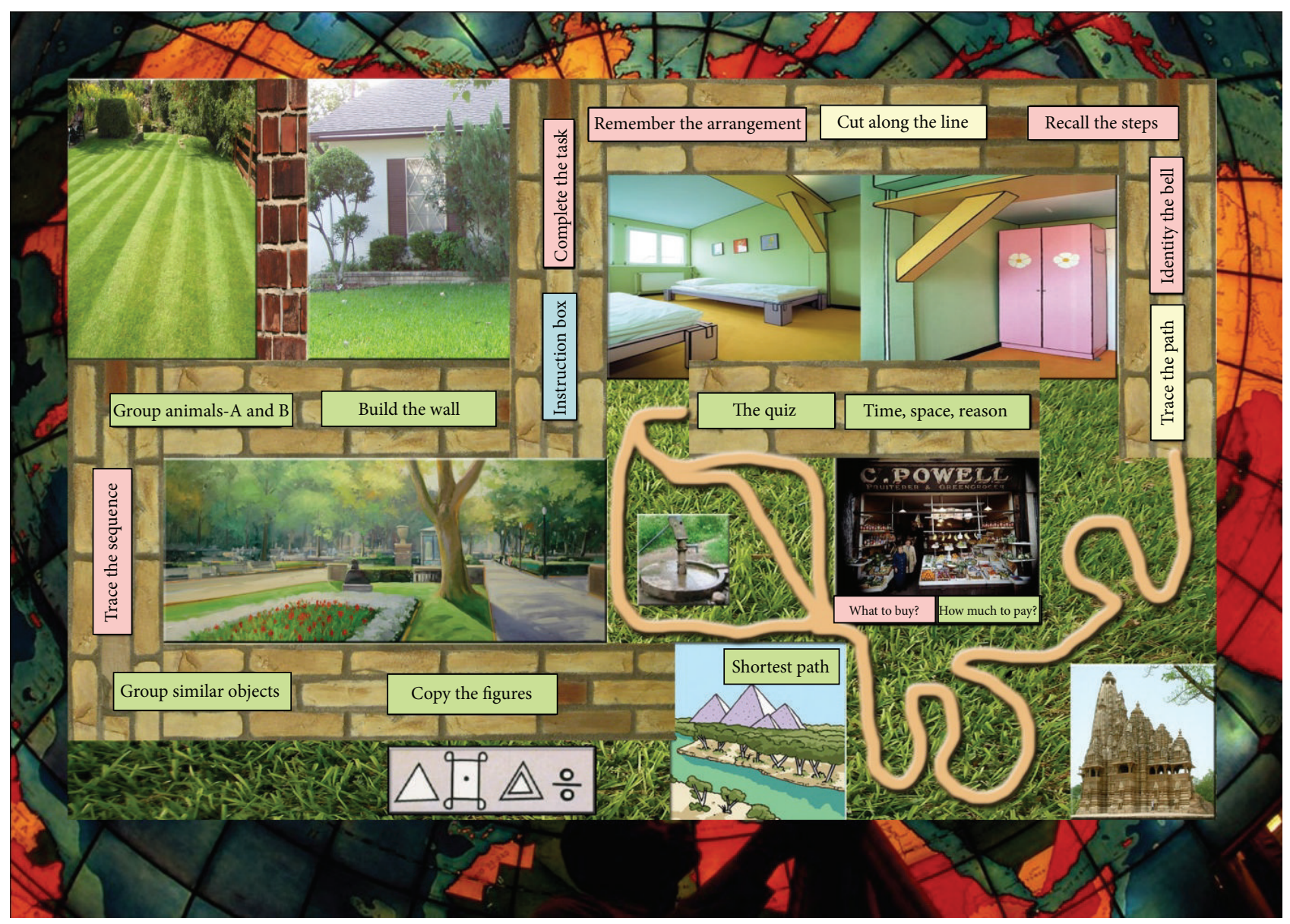

FIgURE 1: MALT test board. The test is administered clock-wise starting from Step 1, "Copy the figures." The red steps test memory, greencognition, and yellow-psychomotor skills. The scores are noted on instruction cum scoring sheet (Table 2).

mental function that each step evaluates. Table 2 shows the instruction cum scoring sheet.

2.2. Interpretation of MALT. To score the performance on MALT, we took into account both accuracy and speed of performance. Based upon the performance of initial 10 controls in the test, we fixed an upper limit of 1 minute for each of steps 3,5, and 6. The maximum scores on the entire test was 60 and 20 each on cognition, memory, and psychomotor skills. Higher scores implied greater impairment in mental function.

Informed consent was obtained from each patient included in the study and the study protocol conforms to the ethical guidelines of the 1975 Declaration of Helsinki as reflected in a priori approval by the ethics committee of Stanley Medical College and Hospital. The study was conducted at the Department of Medical Gastroenterology, Stanley Hospital. Forty proven cirrhotic patients were recruited as cases from among the out-patients and in-patients registered in our department. The diagnosis was based on clinical presentation and ultrasound findings. Patients with neurological deficit, obvious overt encephalopathy, alcohol abuse 72 hours prior to the test, or those on sedatives or psycho-active drugs in the preceding 24 hours were excluded. Patients with cardiac failure, renal disease, and chronic obstructive airway disease were also excluded. It was ensured that the patients had not received lactulose, lactitol, or antibiotics like rifaximin, neomycin, or quinolones in the past three months. Controls were healthy individuals screened at the Master Health Checkup scheme in the hospital.

All controls and patients had critical flicker frequency test using portable battery-powered Hepatonorm Analyzer, Accelab GmbH, Kusterdingen, Germany. The test was done in a quiet dark room. The analyzer evoked an intrafoveal light stimulus with defined pulses [7, 16]. The frequency of pulsation decreased gradually. The patient was asked to press a hand held switch when the change was apparent. The procedure was repeated 5 times to make the subject familiar with the process and 9 readings were recorded. The mean for each patient was calculated. A value below the $38 \mathrm{~Hz}$ mark was considered diagnostic of $\mathrm{MHE}[5,7,16]$.

The subjects (cases and controls) were then brought into a well lit room and were allowed a relaxation time of 15 minutes after which MALT was administered by two trained medical professionals (SD and SM). The patient and the tester are seated across a table with the test board, question cards, 
TABLE 2: MALT instruction cum scoring sheet.

\begin{tabular}{|c|c|c|c|c|}
\hline $\mathrm{Sl}$ & Method of administering the test & $\begin{array}{l}\text { Instruction to fill up the } \\
\text { next column }\end{array}$ & Step score & Final count \\
\hline 1 & $\begin{array}{l}\text { Copy the figures } \\
\text { The subject is asked to draw the shown geometrical figures (printed on the } \\
\text { board) onto a provided ruled paper, without altering the size } \\
\text { (The original figures cross three units on the same paper) }\end{array}$ & $\begin{array}{l}\text { Symmetrical figure...0 } \\
\text { else...1 } \\
\text { Number of units crossed }\end{array}$ & $\cdots$ & . \\
\hline 2 & $\begin{array}{l}\text { Group similar objects } \\
\text { The subject is shown one card (of a set of cards) showing the pictures of a } \\
\text { few things belonging to two different categories (birds and vegetables, say). } \\
\text { The subject is asked to place the blocks of the same color on objects of the } \\
\text { same type }\end{array}$ & $\begin{array}{l}\text { Number of objects } \\
\text { misgrouped }\end{array}$ & $\ldots / 2$ & $\cdots$ \\
\hline 3 & $\begin{array}{l}\text { Trace the sequence } \\
\text { The subject is shown a card to trace a well known sequence (like } \\
\text { seed-sapling-tree-wood log-table) } \\
\text { The examiner waits for a maximum of } 1 \text { minute, else proceeds to the next } \\
\text { step }\end{array}$ & $\begin{array}{l}\text { Score the time in } \\
\text { seconds } \\
0-10 \text { s. . .0, 11-20 s. .1, } \\
21-30 \text { s. . .2, 31-40 s...3, } \\
>40 \text { s...4 }\end{array}$ & $\cdots$ & $\cdots$ \\
\hline \multirow[t]{2}{*}{4} & $\begin{array}{l}\text { Name the animals } \\
\text { A: the subject is shown an animal (a cow, say) and is asked to name it }\end{array}$ & $\begin{array}{l}\text { Score time in seconds } \\
<5 \text { s. . .0, } 5-15 \text { s...1, } \\
>15 \text { s...2 }\end{array}$ & $\cdots$ & $\cdots$ \\
\hline & $\begin{array}{l}\text { B: the subject is asked to separate animals of a certain kind from among the } \\
\text { toys }\end{array}$ & $<15$ s...0, else 1 & $\ldots$ & \\
\hline
\end{tabular}

A well built wall. ..0

Asymmetrical...1

Unable to build. ..2

Build the wall

The subject is asked to build a two layered wall on the given line using the provided blocks The examiner waits for a maximum of 1 minute and then proceeds to the next step

(Asymmetry is defined as inability to place the blocks linearly either along the line in the game board or inability to stack two layers one over the other)

Instruction box

The subject is made to hear three different bell sounds like the alarm, ambulance, and church bell using the audio device. He is also asked to be vigilant about the things he sees in the rest of the game

\section{Complete the task}

The patient is asked to arrange in sequence, the cards depicting the steps of

6 a daily act performed by people at home

The examiner waits for a maximum of 1 minute and then proceeds to the next step

Remember the arrangement

7

The subject is shown an arrangement in the shelf (image available on a question card) and it is narrated once for convenience Immediately following this, the subject is asked to recall the arrangement

Cut along the line

8 The subject is asked to cut along a line with both indentation and curve The graph sheet on the reverse is analyzed for deviation

Recall the steps of the game till this point, in no specific order The examiner asks a question pertaining to the sequence of the steps (what comes after X, say)

10 Identify the sound of the bell One of the three bells sounded in the instruction box is sounded again
Able to complete the

task. . .0

Else. ..1

Number of objects recalled correctly

$(6-\ldots) / 2$

Deviation (in small

units)

$5-10 \ldots 3$

$>10 \ldots .5$

Time (in seconds)

$>45 . . .5$, else. . .0

Number of steps recalled

Correct answer. .. 0

Else. .. 1

Unable to identify. ...1

Else...0 
TABLE 2: Continued.



an audio device, and a table clock. The performance of the patient was noted on the instruction/scoring sheet, including time to completion.

Both MALT and CFF were done in the same sitting. Patients were randomly assigned to MALT or CFF as the first test. Both tests were executed by two different persons (SD and SM) who were blinded to the other examiner's results. The performers administering the tests were trained by experienced clinicians so as to minimize the intra- and interobserver variations.

Chi-square test was used to assess differences between qualitative variables. Student's $t$-test was used to compare the mean CFF values and mean MALT scores between the cases and the controls. Preliminary analyses provided data for receiver-operating characteristic curves to determine the optimum cut-off value for MALT score for the diagnosis of MHE. The best sensitivity and specificity was found at a cutoff score of 20. Using the CFF performance as the reference standard, statistical analysis was performed using Student's $t$ test and the receiver-operating characteristic (ROC) curve. The cirrhotics were classified as "cirrhotics with MHE" and "cirrhotics without MHE," based upon their CFF readings. These groups were compared among themselves and with the control groups. SPSS version 10 was used for all statistical analyses and in the generation of the plots.

The test-retest reproducibility was assessed using the Bland-Altman plot. Twenty subjects including 10 cases and 10 controls were administered MALT twice at an interval of a six hours. It was ensured that patients being evaluated were not on lactulose, lactitol, neomycin, or any sedative meanwhile. The test was administered by the same examiner. The scores of the first and the second session of MALT were compared. The report was prepared in accordance with standards for reporting diagnostic accuracy, STARD guidelines (Figure 2) [17].

\section{Results}

3.1. Demographic and Subject Characteristics. The study comprised of 40 patients with cirrhosis (hereinafter referred to as "cases") and included 25 males (62.5\%). There were 36 healthy controls (hereinafter referred to as "controls") and included 16 males $(44.44 \%)$. The base line characteristics of controls and cases are shown in Table 3. The mean age of the cases and controls was significantly different $(P=0.04)$. There was no difference in sex distribution $(P=0.18)$, educational status $(P=0.93)$, and monthly income $(P=0.09)$ among the cases and the controls.

The etiology of cirrhosis was alcohol in 15 patients (37.5\%), HCV in 13 (32.5\%), nonalcoholic fatty liver disease in $6(17.5 \%)$, autoimmune in $1(2.5 \%)$, and cryptogenic in 8 (20\%). There were 22 patients (55\%) belonging to ChildPugh class A and 18 (45\%) to class B. Among the cirrhotics, there were 18 variceal bleeders (45\%) and 2 patients $(5 \%)$ 




FIGURE 2: Study design flowchart according to the STARD guidelines.

had coagulopathy. 4 patients (10\%) had refractory ascites, 2 patients $(5 \%)$ had spontaneous bacterial peritonitis, and 8 others (20\%) had urosepsis.

3.2. Critical Flicker Frequency. Using $38 \mathrm{~Hz}$ as CFF cut-off for MHE, 16 out of the 40 cirrhotics had MHE (40\%), 8 each (50\%) belonged to Child Class A and Child Class B. Among the 24 cirrhotics without MHE, 14 (58.33\%) belonged to Child A and $10(41.66 \%)$ to Child B at the time of MHE testing. The mean CFF for the cases was $39 \pm 4.2 \mathrm{~Hz}$ compared to $42 \pm 1.9 \mathrm{~Hz}$ among the controls $(P=0.00)$ (Figure 3(a)). The demographic characteristics and the lab parameters of the MHE and non-MHE groups among the cirrhotics or the "cases" are compared in Table 4.

3.3. MALT. The cases performed worse than controls on MALT. The controls scored $10 \pm 5$ compared to the cases, who scored $18 \pm 8$ (Figure 3(b)). This difference was significant $(P=0.00)$. On plotting the ROC curve (Figure 4(a)), the sensitivity and the specificity were found to be $94 \%$ and $83 \%$, respectively, for a cut-off value set at 20. Using ROC with $\mathrm{CFF}$ as the gold standard, the AUC for diagnosis of MHE using MALT score was $89 \%$. Figure 3(b) compares the mean MALT scores of MHE, non-MHE cirrhotics, and controls. MHE patients scored higher than the non-MHE and controls using the 20 mark as cut-off.

3.4. Test-Retest Variability. The test-retest variability was assessed using the intraclass correlation coefficient, ICC = $0.894(P=0.000)$. The Bland-Altman plot (Figure 4(b)) shows that the MALT retest scores of the 10 cases and 10 controls (who were subjected to the same test at an interval of 6 hours) was in agreement with the initial test scores.

3.5. Other Considerations. The Hepatonorm analyzer, manufactured in Germany, is an electronic device which runs on a battery that needs to be regularly changed. The price per unit is US $\$ 3053$ and one day long user training costs US $\$ 230$. The MALT board and its kit cost approximately US $\$ 5$. The cost
TABLE 3: Demographic characteristics of cases and controls.

\begin{tabular}{lcc}
\hline $\begin{array}{l}\text { Demographic characteristic } \\
(\text { Mean } \pm \text { SD) }\end{array}$ & $\begin{array}{c}\text { Controls } \\
(n=36)\end{array}$ & $\begin{array}{c}\text { Cases } \\
(n=40)\end{array}$ \\
\hline Age (years) & $42 \pm 9.7^{*}$ & $46 \pm 8.3^{*}$ \\
$\begin{array}{l}\text { Male : female } \\
\text { Education }\end{array}$ & $16 / 20$ & $25 / 15$ \\
$\begin{array}{l}\text { (not educated/educated) } \\
\begin{array}{l}\text { Income per month (in US } \\
\text { dollars) }\end{array}\end{array}$ & $13 / 23$ & $13 / 27$ \\
${ }^{*} P<0.05$. & $15.36 \pm 14.51$ & $10.77 \pm 7.40$ \\
& &
\end{tabular}

ratio is of the order of $10^{5}$. The mean time of administration for both MALT and CFF was $10 \pm 2$ minutes.

\section{Discussion}

The highlights of the study are (a) a significant correlation between CFF and MALT scores in the population under study $(P<0.05)$; (b) the ROC curve and the box-whisker plots indicate that MALT is a highly sensitive and specific test considering CFF as the standard; and (c) the intraclass correlation coefficient was 0.894 on assessment of test-retest variability. The sensitivity and specificity of MALT was found to be $94 \%$ and $83 \%$, respectively, compared to earlier reported $72.4 \%$ and $77.2 \%$ for CFF when the cut-off is set at $38 \mathrm{~Hz}$ [18]. Though MALT may be seen to be a time taking procedure, the mean time taken for MALT and CFF did not vary significantly. The former is inexpensive test compared to CFF.

A number of neuropsychological tools have been used to diagnose cognitive deficits in patients with cirrhosis. These include an extended neuropsychological assessment, shorter batteries, and computerized tests. The extended neuropsychological assessment is based upon the expert judgment and is difficult to validate [19]. The two shorter batteries-RBANS (Repeatable Battery for Assessment of Neuropsychological Status) and PHES (Psychometric Hepatic Encephalopathy Score) are primarily paper-pencil tests. The performance on these tests is affected by the level of literacy and on the familiarity of the subject to paper and pencil among the literates. However, these tests have their own advantages. RBANS is validated on a large normative data, it is available in multiple languages and has parallel versions available for repeated testing. However, most studies are in Alzheimer's patients and the studies in cirrhotics are only few [20]. PHES was originally validated in a series of nonalcoholic patients in Germany and has normative data available from some countries. However, our knowledge of MHE has grown since those studies and, now, it is understood that an ideal diagnostic tool should reflect on those daily activities which affect the quality of life, the ability to drive, and so forth, which are often impaired in MHE [21, 22]. To overcome the shortcoming of these short batteries for the use in resource-limited settings including their dependence on the literacy level, the figure connection test (FCT) was reported by a group in India [9]. However, FCT only tests a discrete cognitive domain impaired in MHE. Computerized neuropsychological tests include cognitive drug research (CDR), inhibitory control 


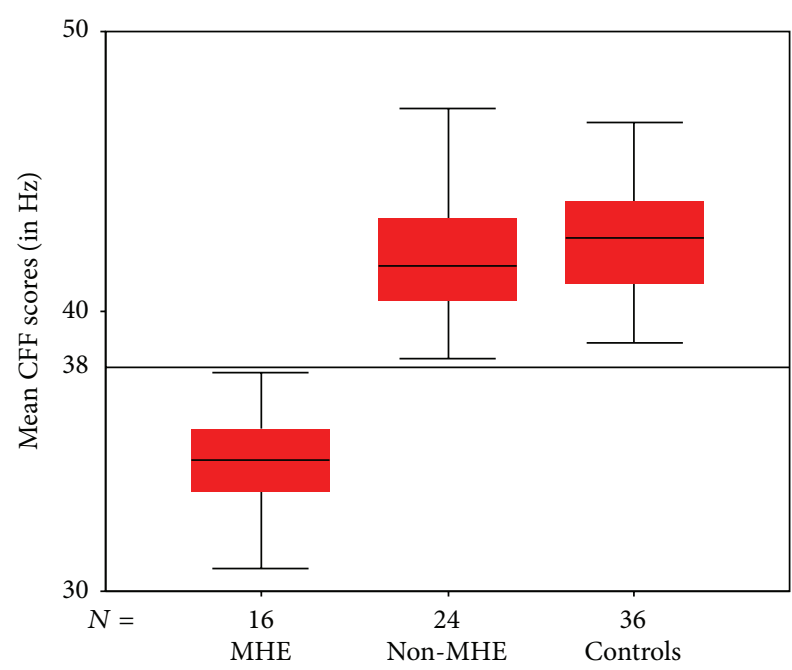

(a)



(b)

FIGURE 3: Intergroup comparison for CFF reading and MALT scores. The panel (a) compares the CFF readings between the controls, the non-MHE cirrhotics, and MHE (+) cirrhotics. The panel (b) compares the MALT scores between the same groups.

TABLE 4: Demographics within the cirrhosis group.

\begin{tabular}{|c|c|c|}
\hline & $\begin{array}{l}\text { Cirrhotics without } \\
\text { MHE } \\
(\text { CFF- }) \\
(n=24)\end{array}$ & $\begin{array}{l}\text { Cirrhotics with MHE } \\
\qquad \begin{array}{c}(\mathrm{CFF}+) \\
(n=16)\end{array}\end{array}$ \\
\hline Age & $43.5 \pm 8.1^{*}$ & $50 \pm 7.2^{*}$ \\
\hline Years of education & $6.4 \pm 4.5^{*}$ & $3.06 \pm 3.7^{*}$ \\
\hline Gender $(\mathrm{M} / \mathrm{F})$ & $16 / 8$ & $9 / 7$ \\
\hline Cirrhosis etiology (Alcohol/HCV/HCV+Alcohol/NASH/Others) & 09/05/00/04/06 & 03/05/03/02/03 \\
\hline MELD score (median) & 11 & 14 \\
\hline Child score (A/B) & $14 / 10$ & $8 / 8$ \\
\hline Total bilirubin (median) & 1.5 & 1.6 \\
\hline INR (median) & $1.1^{*}$ & $1.3^{*}$ \\
\hline Serum creatinine (median, in $\mathrm{mg} / \mathrm{dL}$ ) & $0.73^{*}$ & $0.86^{*}$ \\
\hline MALT scores & $14.8 \pm 7.8^{\dagger}$ & $24.8 \pm 3.5^{\dagger}$ \\
\hline
\end{tabular}

${ }^{*} P<0.05$ between two groups.

${ }^{\dagger} P<0.01$ between two groups.

test (ICT), and the scan test which have been validated in the UK, USA, and Italy, respectively [23-25]. We do not have the validation data for these tests in our population.

The introduction of MALT has been based on the fundamental assumption that the currently available tests for the diagnosis of MHE are designed to test for one or two domains of mental impairment, and are expensive or not widely available [10]. MALT was designed to include tasks performed on a day-to-day routine basis. In the population under study, more than $36 \%$ of the participants were illiterate and the remaining who were literate were not used to paper and pencil. This is in line with the "demise of the pencil" reported by Iduru and Mullen [22]. Moreover, age and education correction factors are absent for Psychometric Hepatic Encephalopathy Score (PHES) in our population.
The prevalence of MHE among the cirrhotics in the present study is $40 \%$. It is in agreement with the prevalence of $41 \%$ reported in a recent study involving 200 cirrhotics from North India while on the higher side compared to 30\% reported in the study from Spain using PHES $[18,26]$. It would either signify that MALT included more true positives or that the prevalence is different in our population $[27,28]$.

MALT is a psychometric test which displays day-today activity on a colorful board and disagreement between administrators of the test is significantly less (85\% agreement in interobserver studies). Though the tasks on the game board remain the same, the elements of the tasks are not printed on the board but on multiple cards. This is to avoid a memory effect that accompanies any psychometric test. MALT includes steps like "build the wall" and "trace the 


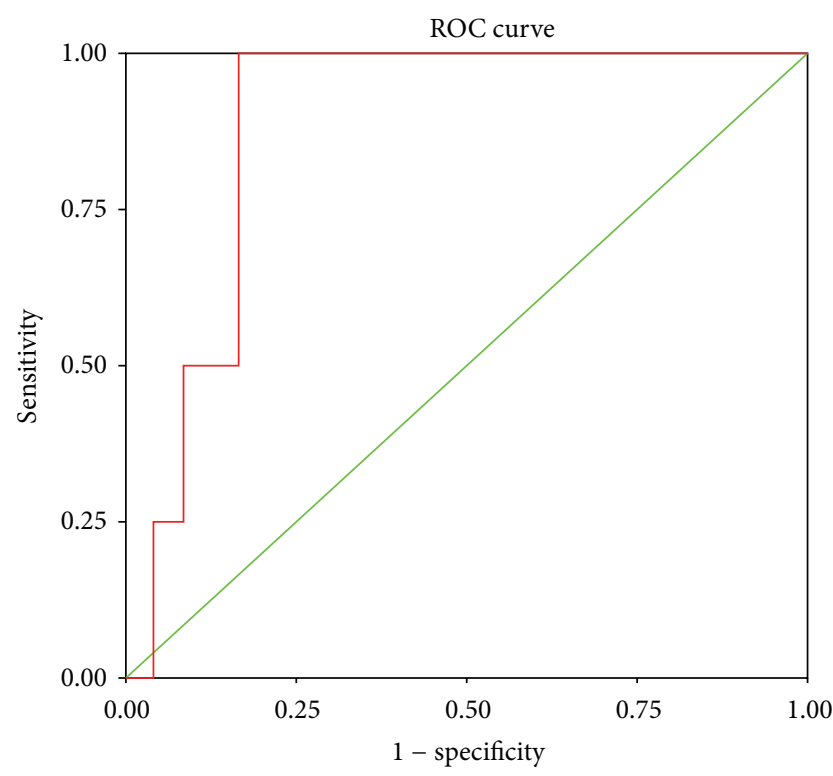

(a)

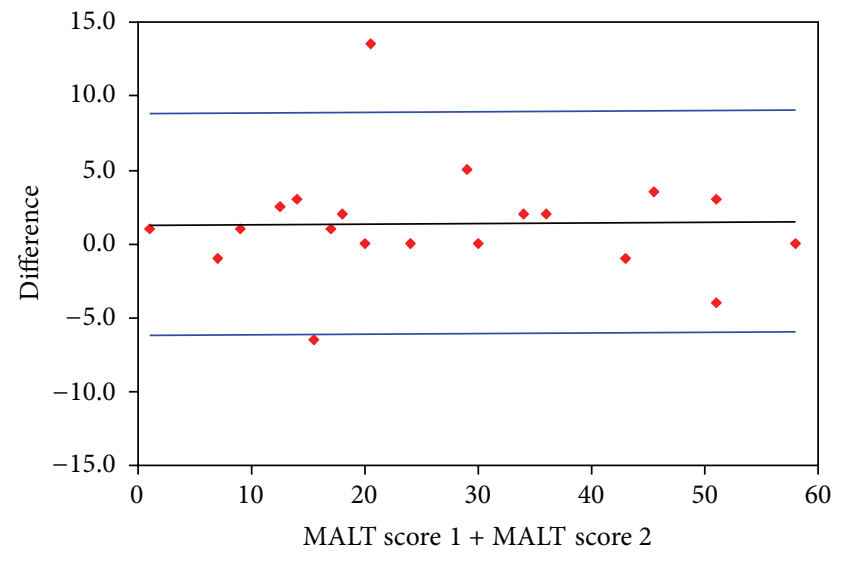

(b)

FIGURE 4: (a) ROC curve using CFF as gold standard and MALT score 20 as cut-off for the diagnosis of MHE. (b) Bland-Altman plot for the test-retest agreement of MALT.

path" which are analogous to block design and trail tracing test. In MALT, the subject is not asked to connect numbers, but rather to trace the sequence of a day-to-day event from morning to night, which in true sense does not need a level of literacy.

Although the majority of surveyed hepatologists in Spain and the United States agreed that MHE was a significant problem requiring testing during out-patient visits, only a few were able to actually perform the test during their dayto-day clinical practice $[29,30]$. MALT needs validation in large number of patients. In the future, when the test is available in the form of a touch screen audio-visual videogame, the test could be self-administered by the patient during the wait period in the clinic. Moreover, MALT is in the form of a colorful board. It might be interesting to note if administration of such a test has any effect on the mood and affect of the depressed cirrhotic. It will also be of interest to follow up MALT scores of patients on therapy like lactulose for hepatic encephalopathy. Also, to see a head to head analysis of MALT compared to other psychometric tests in future. However, these were beyond the scope of the present study. The choice of CFF as the gold standard in the current study was also to circumvent many problems known to be encountered with administering multiple psychometric tests $[2,31]$.

This study largely aimed to design a psychometric battery to diagnose $\mathrm{MHE}$ in our population, which is useful for the illiterate patients and to check its reliability. The high sensitivity and specificity of MALT, its ease of administration, reproducibility, and cost-effectiveness seen in this pilot beckon further validation studies involving larger sample sizes.

\section{Conflict of Interests}

The authors declare that there is no conflict of interests regarding the publication of this paper.

\section{References}

[1] J. S. Bajaj, M. Hafeezullah, Y. Zadvornova et al., "The effect of fatigue on driving skills in patients with hepatic encephalopathy," The American Journal of Gastroenterology, vol. 104, no. 4, pp. 898-905, 2009.

[2] P. Sharma, B. C. Sharma, V. Puri, and S. K. Sarin, "Critical flicker frequency: diagnostic tool for minimal hepatic encephalopathy," Journal of Hepatology, vol. 47, no. 1, pp. 67-73, 2007.

[3] C. Wein, B. Popp, H. Koch, G. Oehler, and P. Schauder, "Minimal hepatic encephalopathy impairs fitness to drive," Hepatology, vol. 39, no. 3, pp. 739-745, 2004.

[4] A. T. Blei and J. Córdoba, "Hepatic encephalopathy," The American Journal of Gastroenterology, vol. 96, no. 7, pp. 19681976, 2001.

[5] M. Romero-Gómez, F. Boza, M. S. García-Valdecasas, E. García, and J. Aguilar-Reina, "Subclinical hepatic encephalopathy predicts the development of overt hepatic encephalopathy," The American Journal of Gastroenterology, vol. 96, no. 9, pp. 27182723, 2001.

[6] J. S. Bajaj, M. Hafeezullah, J. Franco et al., "Inhibitory control test for the diagnosis of minimal hepatic encephalopathy," Gastroenterology, vol. 135, no. 5, pp. 1591.el-1600.el, 2008.

[7] G. Kircheis, W. E. Fleig, R. Görtelmeyer, S. Grafe, and D. Häussinger, "Assessment of low-grade hepatic encephalopathy: a critical analysis," Journal of Hepatology, vol. 47, no. 5, pp. 642650, 2007.

[8] K. Weissenborn, N. Rückert, H. Hecker, and M. P. Manns, “The number connection tests $\mathrm{A}$ and $\mathrm{B}$ : interindividual variability 
and use for the assessment of early hepatic encephalopathy," Journal of Hepatology, vol. 28, no. 4, pp. 646-653, 1998.

[9] R. K. Dhiman, V. A. Saraswat, M. Verma, and S. R. Naik, "Figure connection test: a universal test for assessment of mental state," Journal of Gastroenterology and Hepatology, vol. 10, no. 1, pp. 1423, 1995.

[10] S. Iduru, K. Hisamuddin, and K. D. Mullen, "Minimal hepatic encephalopathy: simplifying its diagnosis," The American Journal of Gastroenterology, vol. 102, no. 7, pp. 1537-1538, 2007.

[11] J. Bajaj, "Minimal hepatic encephalopathy matters in daily life," World Journal of Gastroenterology, vol. 14, no. 23, pp. 3609-3615, 2008.

[12] P. Ferenci, A. Lockwood, K. Mullen, R. Tarter, K. Weissenborn, and A. T. Blei, "Hepatic encephalopathy-definition, nomenclature, diagnosis, and quantification: final report of the Working Party at the 11th World Congresses of Gastroenterology, Vienna, 1998," Hepatology, vol. 35, no. 3, pp. 716-721, 2002.

[13] H. Schomerus and W. Hamster, "Quality of life in cirrhotics with minimal hepatic encephalopathy," Metabolic Brain Disease, vol. 16, no. 1-2, pp. 37-41, 2001.

[14] N. Kumar, C. Shekhar, P. Kumar, and A. S. Kundu, "Kuppuswamy's socioeconomic status scale-updating for 2007," The Indian Journal of Pediatrics, vol. 74, no. 12, pp. 1131-1132, 2007.

[15] D. J. Siegel, "Perception and cognition," in Kaplan and Sadock's Synopsis of Psychiatry: Behavioral Sciences/Clinical Psychiatry, B. Kaplan and V. Kaplan, Eds., pp. 45-50, Lippincott Williams \& Wilkins, Philadelphia, Pa, USA, 9th edition, 2003.

[16] G. Kircheis, N. Hilger, and D. Häussinger, "Value of critical flicker frequency and psychometric hepatic encephalopathy score in diagnosis of low-grade hepatic encephalopathy," Gastroenterology, vol. 146, no. 4, pp. 961.ell-969.el1, 2014.

[17] P. M. Bossuyt, J. B. Reitsma, D. E. Bruns et al., "Towards complete and accurate reporting of studies of diagnostic accuracy: the STARD initiative," Clinical Chemistry and Laboratory Medicine, vol. 41, no. 1, pp. 68-73, 2003.

[18] M. Romero-Gómez, J. Córdoba, R. Jover et al., "Value of the critical flicker frequency in patients with minimal hepatic encephalopathy," Hepatology, vol. 45, no. 4, pp. 879-885, 2007.

[19] J. Córdoba, "New assessment of hepatic encephalopathy," Journal of Hepatology, vol. 54, no. 5, pp. 1030-1040, 2011.

[20] S. Mooney, T. I. Hasssanein, R. C. Hilsabeck et al., "Utility of the Repeatable Battery for the Assessment of Neuropsychological Status (RBANS) in patients with end-stage liver disease awaiting liver transplant," Archives of Clinical Neuropsychology, vol. 22, no. 2, pp. 175-186, 2007.

[21] K. Weissenborn, J. C. Ennen, H. Schomerus, N. Rückert, and H. Hecker, "Neuropsychological characterization of hepatic encephalopathy," Journal of Hepatology, vol. 34, no. 5, pp. 768773, 2001.

[22] S. Iduru and K. D. Mullen, "The demise of the pencil? New computer-assisted tests for minimal hepatic encephalopathy," Gastroenterology, vol. 135, no. 5, pp. 1455-1456, 2008.

[23] H. Mardini, B. K. Saxby, and C. O. Record, "Computerized psychometric testing in minimal encephalopathy and modulation by nitrogen challenge and liver transplant," Gastroenterology, vol. 135, no. 5, pp. 1582-1590, 2008.

[24] J. S. Bajaj, K. Saeian, M. D. Verber et al., "Inhibitory control test is a simple method to diagnose minimal hepatic encephalopathy and predict development of overt hepatic encephalopathy," The American Journal of Gastroenterology, vol. 102, no. 4, pp. 754-760, 2007.
[25] P. Amodio, P. Marchetti, F. del Piccolo et al., "Study on the sternberg paradigm in cirrhotic patients without overt hepatic encephalopathy," Metabolic Brain Disease, vol. 13, no. 2, pp. 159172,1998

[26] P. Sharma and B. C. Sharma, "Predictors of minimal hepatic encephalopathy in patients with cirrhosis," Saudi Journal of Gastroenterology, vol. 16, no. 3, pp. 181-187, 2010.

[27] A. Das, R. K. Dhiman, V. A. Saraswat, M. Verma, and S. R. Naik, "Prevalence and natural history of subclinical hepatic encephalopathy in cirrhosis," Journal of Gastroenterology and Hepatology (Australia), vol. 16, no. 5, pp. 531-535, 2001.

[28] R. K. Dhiman, V. A. Saraswat, B. K. Sharma et al., "Minimal hepatic encephalopathy: consensus statement of a working party of the Indian National Association for Study of the Liver," Journal of Gastroenterology and Hepatology, vol. 25, no. 6, pp. 1029-1041, 2010.

[29] J. S. Bajaj, A. Etemadian, M. Hafeezullah, and K. Saeian, "Testing for minimal hepatic encephalopathy in the United States: an AASLD survey," Hepatology, vol. 45, no. 3, pp. 833-834, 2007.

[30] M. Vergara-Gómez, M. Flavià-Olivella, M. Gil-Prades, B. Dalmau-Obrador, and J. Córdoba-Cardona, "Diagnosis and treatment of hepatic encephalopathy in Spain: results of a survey of hepatologists," Gastroenterologia y Hepatologia, vol. 29, no. 1, pp. 1-6, 2006.

[31] J. Varghese, M. A. Thiravia, B. Natarajan, and J. Venkataraman, "Critical flicker test: yet another tool for minimal hepatic encephalopathy," European Journal of Gastroenterology and Hepatology, vol. 19, no. 11, p. 1031, 2007. 


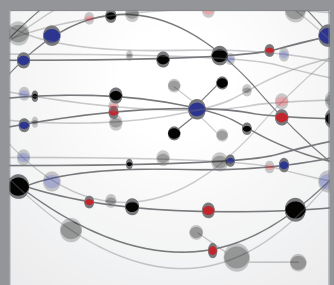

The Scientific World Journal
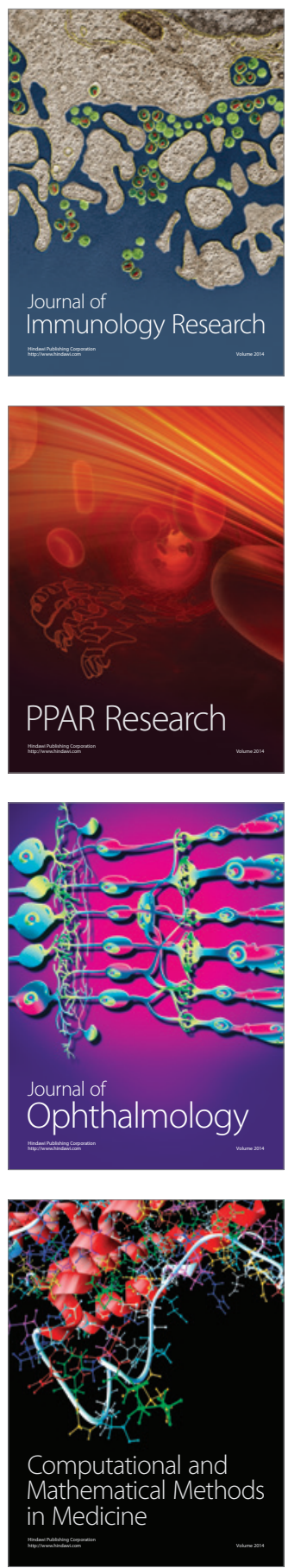

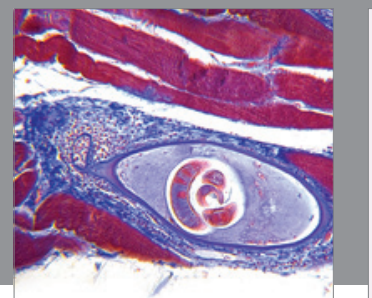

Gastroenterology

Research and Practice
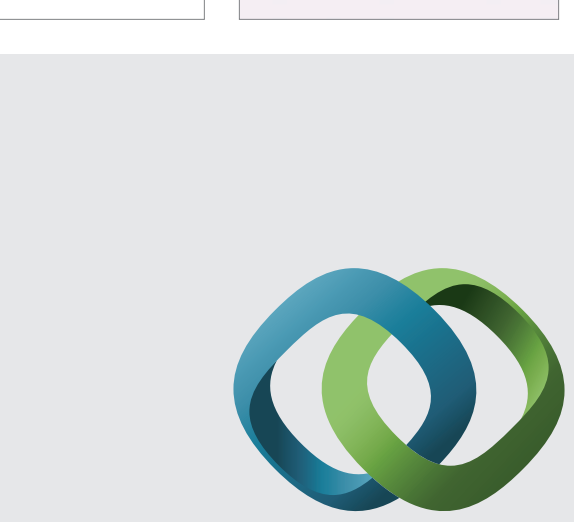

\section{Hindawi}

Submit your manuscripts at

http://www.hindawi.com
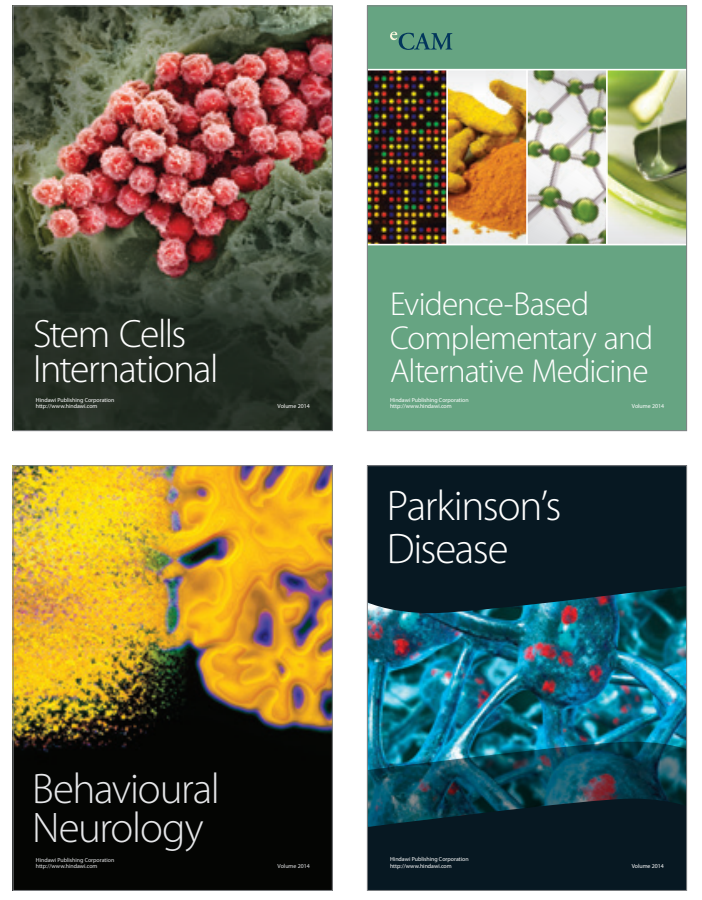
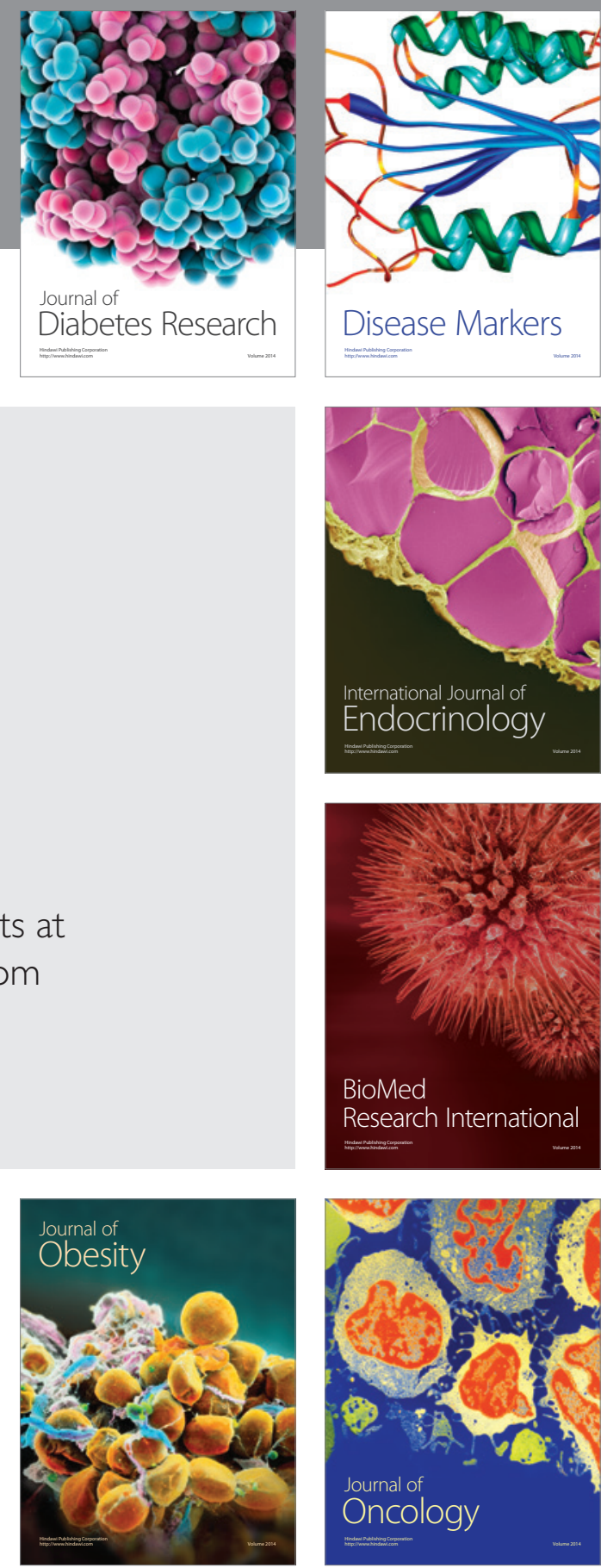

Disease Markers
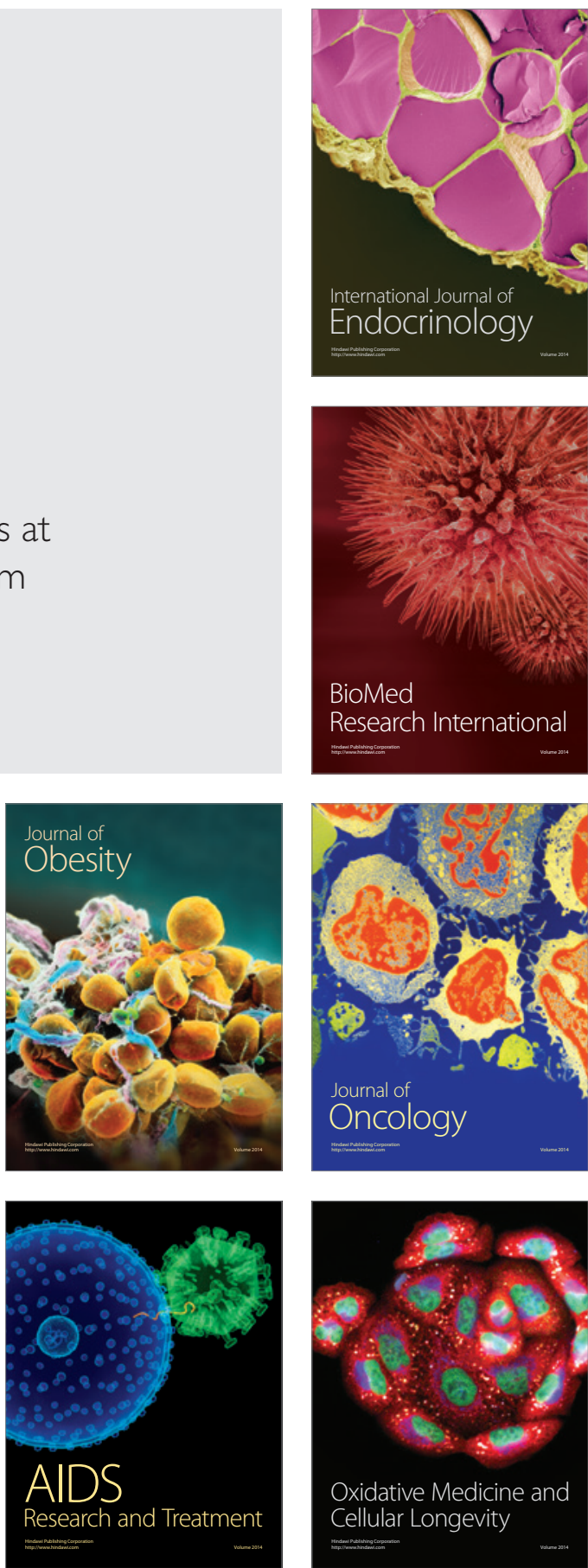